\title{
The Health Workers and Delivery Process Related Maternal Satisfaction with Delivery Services at UDUTH Sokoto, Nigeria
}

\author{
Lawali Yakubu* and Lamide A
}

Department of Nursing Sciences, Faculty of Clinical Sciences, Nigeria

\section{ISSN: 2640-9666}

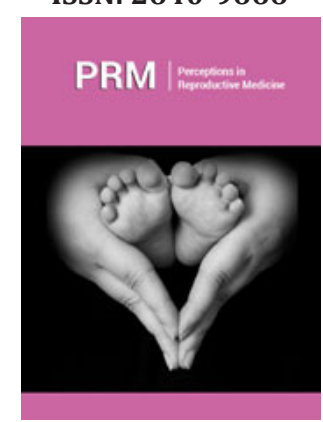

*Corresponding author: Lawali Yakubu, Department of Nursing Sciences, Faculty of Clinical Sciences, Nigeria

Submission: 䀯 March 05, 2020

Published: 盏March 17, 2020

Volume 3 - Issue 5

How to cite this article: Lawali Yakubu, Lamide A. The Health Workers and Delivery Process Related Maternal Satisfaction with Delivery Services at UDUTH Sokoto, Nigeria. Perception in Reproductive Medicine.3(5). PRM.000573.2020.

DOI: 10.31031/PRM.2020.03.000573

Copyright@ Lawali Yakubu, This article is distributed under the terms of the Creative Commons Attribution 4.0 International License, which permits unrestricted use and redistribution provided that the original author and source are credited.

\begin{abstract}
Every pregnancy and child birth comes with a specific experience and none is guaranteed to be safe. Positive delivery experiences facilitate the further use of the reproductive health services and vice versa. The objective of the present investigation was to determine the maternal satisfaction towards delivery services at Usmanu Danfodiyo University Teaching Hospital Sokoto. A cross-sectional descriptive study was used. The study was conducted on a sample of 158 postnatal women at UDUTH. The study participants were selected using convenient method of sampling and the data was collected using self-administrated questionnaires. Most of the respondents are within the age range of 30-39 71(49.3\%) and most of which are Hausas by tribe $57(39.6 \%)$. The finding of the study shows that, majority of the women were satisfied with all the process/health workers related factors except for the sex of health care provider who attended to them. Also, majority of the women were satisfied with most of the maternal obstetrics history related factors. However, most of them were not satisfied with assisted delivery services, complicated outcome of delivery as well as loss of child during or after delivery. In conclusion there is a high level of maternal satisfaction with delivery services in UDUTH Sokoto. The study recommended that, condition of toilets and shower rooms in the delivery room and postnatal ward should be addressed to ensure the satisfaction of maternity clients. Government should make infrastructural improvements to overcome shortages of water and electricity, toilet and shower supplies.
\end{abstract}

Keywords: Maternal; Satisfaction; Delivery services pregnancy

\section{Introduction}

With all the global efforts to overcome the pregnancy related deaths, deaths still remain an issue of concern in developing countries. These deaths are almost always preventable through the attendance of pregnancy and deliveries by skilled healthcare professionals in adequately supplied and equipped health facilities [1]. The causes of maternal mortality can be describe as: direct obstetric causes $(73 \%)$ and indirect causes $(27 \%)$ with the major causes being haemorrhage (27.1\%), hypertensive disorders (14\%), sepsis (10.7\%), abortion $(7.9 \%)$, and embolism (3.2\%) [2]. Thus, the Global Strategy for Women's, Children's and Adolescents' Health (2016-2030) envisions a world in which every woman, child, and adolescent in every setting realizes his/her rights to physical and mental health and well-being, has social and economic opportunities, and is able to participate fully in shaping prosperous and sustainable societies [3]. Childbirth is a crucial experience in a women's life as it has a substantial psychological, emotional, and physical impact. A positive experience in childbirth is important to the woman, infant's health and well-being, and mother-infant relationship. Furthermore, it is useful for the care providers to guarantee the best preparation, health service, and support to childbearing women [4]. Memories and experiences of childbirth remain with the woman throughout her life. Clearly, the support and care they receive during this period is critical. Patient satisfaction is a major component of the quality of health care in service provision. Patient expectations of care and attitudes greatly contribute to satisfaction [5]. Mostly, maternal satisfaction is determined by the physical environment of the health service, and the availability and accessibility of medicines and supplies.

It is also affected by interpersonal communication with the health care provider, competency of the health care provider and support, and the health status of the mother and newborn [6]. Satisfaction during intrapartum care is the most influential attribute on service return behaviors and utilization [7]. Assessment of satisfaction with maternity services is crucial and helps in the future utilization of service [8]. Understanding and addressing them as part of quality-improvement programme can make delivery care safe, 
affordable, and respectful. In short, Ubiquinone et al. [9] assert that, continuity of maternal and childcare is related to the levels of satisfaction of mother and family members with health providers and health facilities. Despite that, little is known about the maternal satisfaction with delivery services at UDUTH. Hence the need for the study.

\section{Research Design}

A descriptive survey design was used for this study to elicit maternal satisfaction with delivery services at Usmanu Danfodiyo University teaching hospital (UDUTH) Sokoto.

\section{Target population}

All mothers who gave birth in Usmanu Danfodiyo University (UDUTH) Sokoto in the labor ward and theatre at the time of data collection that fulfilled the selection criteria.

\section{Inclusion criteria}

1. Women who gave birth in UDUTH within the data collection time

2. Postnatal mothers 'who were mentally or critically well after delivery.

\section{Exclusion criteria}

1. Women who gave birth in UDUTH outside the data collection time

2. Postnatal mothers 'who were mentally or critically ill were not included in the study subjects.

\section{Sampling size determination}

The sample size was derived from the average deliveries conducted in the month of August 2019 in the labor ward in UDUTJH Sokoto (Table 1). Therefore, the calculated sample size is 158, and a total of 158 questionnaires will be used.

Table 1: The average delivery conducted in the month of August 2019 in the labor ward in UDUTJH Sokoto.

\begin{tabular}{|c|c|c|}
\hline S/no. & Type of Delivery & $\begin{array}{c}\text { Total Number of Live } \\
\text { Birth }\end{array}$ \\
\hline 1. & Spontaneous vaginal delivery & 221 \\
\hline 2. & Cesarean section & 32 \\
\hline 3. & Still birth & 4 \\
\hline 4. & Vacuum delivery & 3 \\
\hline & Total & 260 \\
\hline
\end{tabular}

Using the Slovin's rule:

$\mathrm{n}=\mathrm{N} /(1+\mathrm{Ne} 2)$

Where $\mathrm{n}=$ the minimum sample size required, $\mathrm{N}=$ study population $=260$

$\mathrm{e}=$ the margin of error at $95 \%$ confidence level

The sample size $(n)=260 /(1+260 \times(0.05) 2)$

$n=260 /(1+260 \times 0.0025)$

$$
\begin{aligned}
& \mathrm{n}=260 / 1+0.65 \\
& \mathrm{n}=260 / 1.65 \\
& \mathrm{n}=157.58 \\
& \mathrm{n}=158
\end{aligned}
$$

\section{Sampling technique}

A convenient sampling technique was used in this study. Convenient non-probability sampling technique on the other hand is the type of sampling technique that involves the use of a target population that is available at the time of data collection without any selection criteria.

\section{Instrument for data collection}

1. The instrument used for data collection was questionnaires. The questionnaire is divided into four sections: A, B, C and D.

2. Section A comprises of socio-demographic data of respondents.

3. Section B comprises of research questions on structural/ health facility related to maternal satisfaction with the delivery services.

4. Section C comprises of research questions on process/ health workers related to maternal satisfaction with the delivery services.

5. Section D comprises of research questions on maternal obstetrics history related maternal satisfaction with delivery services.

The questionnaire is close ended type.

\section{Method of Data Analysis}

The data collected were organized and presented using descriptive statistics in the form of frequency tables. The result will be analyzed using a statistical package for social sciences (SPSS) version 20. A decision mean of 3.0 will be used to ascertain the satisfaction or non-satisfaction of the respondent to the questionnaire items.

Measurement scale:

Less than 3.0 is unsatisfied.

3.0 and above is satisfied.

\section{Ethical consideration}

Permission was obtained from the departmental research committee to carry out the study. The culture and religion of the subjects were considered and respected. Individual verbal consent was obtained from respondents after full explanation of what the projectentails by the researcher in the questionnaire. Confidentiality was also maintained, and a serial number rather than names was written on the questionnaires to ensure anonymity. The copy of this research work would only be available in the department library for reference and for further study. 


\section{Data analysis}

Section A: Socio-demographic data: The Table 2 shows that out of the 144 respondents, 71 were between the age-range of 30$39(49.3 \%)$ which formed the majority of the respondents, followed by those within the age range of 20-29(34.0\%). 13 are within the age range of 40 and above $(9.1 \%)$ and those within the age range of $10-19(7.6 \%)$ forms a minority of the respondents. Out of the 144 respondents; $57(39.6 \%)$ are Hausa by tribe, $28(19.4 \%)$ are Yoruba by tribe, $26(18.0 \%)$ are Igbo and the remaining $33(28.0 \%)$ are of other tribes which includes the Fulani, Gbagi, Igbira, Igala and Nupe. Out of the 144 respondents; $102(70.8 \%)$ are Muslims, and the other $42(29.2 \%)$ are Christians. 122 of the respondents are married (84.7\%), 14(9.7\%) single, and others comprised $4.2 \%$ and $1.4 \%$ were divorced or widowed, respectively. Of all the participants, $24(16.7 \%), 48(33.3 \%) \& 39(29.1 \%)$ were primary, secondary and higher education certificate holders. While few have Islamic education, $21(14.6 \%)$ and $12(8.3 \%)$ had no formal education. The Majority of the respondent are unemployed women $41(28.5 \%)$, students $36(25 \%)$ and government employees $35(24.3 \%)$, private employees $18(12.5 \%)$ and self-employed women 14(9.7\%) (Table 3).

Table 2: Socio-demographic data of mothers.

\begin{tabular}{|c|c|c|c|}
\hline S/no & Socio-Demographic Data & Frequency & Percentage \\
\hline 1. & \multicolumn{3}{|c|}{ Age } \\
\hline & $10-19$ & & 7.6 \\
\hline & $20-29$ & 49 & 34.0 \\
\hline & $30-39$ & 71 & 49.3 \\
\hline & 40 and above & 13 & 9.1 \\
\hline & Total & 144 & 100 \\
\hline \multirow[t]{6}{*}{2.} & \multicolumn{3}{|c|}{ Ethnic group } \\
\hline & Hausa & 57 & 39.6 \\
\hline & Igbo & 26 & 18.0 \\
\hline & Yoruba & 28 & 19.4 \\
\hline & Others & 33 & 23.0 \\
\hline & Total & 144 & 100 \\
\hline \multirow[t]{5}{*}{3.} & \multicolumn{3}{|c|}{ Religion } \\
\hline & Islam & 102 & 70.8 \\
\hline & Christianity & 42 & 29.2 \\
\hline & Others & - & - \\
\hline & Total & 144 & 100 \\
\hline \multirow[t]{5}{*}{4.} & \multicolumn{3}{|c|}{ Marital status } \\
\hline & Single & 14 & 9.7 \\
\hline & Married & 122 & 84.7 \\
\hline & Divorced & 06 & 4.2 \\
\hline & Widowed & 02 & 1.4 \\
\hline
\end{tabular}

Table 3: Process/health workers related maternal satisfaction with delivery services.

\begin{tabular}{|c|c|c|c|c|}
\hline S/N & Items & Mean & $\begin{array}{c}\text { Standard } \\
\text { Deviation }\end{array}$ & Remark \\
\hline 1. & $\begin{array}{c}\text { I am satisfied with the } \\
\text { Waiting time before being } \\
\text { attended to by the health } \\
\text { workers }\end{array}$ & 3.49 & 1.46 & Satisfied \\
\hline 2. & $\begin{array}{c}\text { I am satisfied with the } \\
\text { Respect and courtesy by } \\
\text { health workers }\end{array}$ & 4.12 & 1.47 & Satisfied \\
\hline 3. & $\begin{array}{c}\text { I am satisfied with the } \\
\text { Amount of time spent on } \\
\text { examinations }\end{array}$ & 4.58 & 1.03 & Satisfied \\
\hline 4. & $\begin{array}{c}\text { I am satisfied with the } \\
\text { Competency and confidence } \\
\text { the of the health workers }\end{array}$ & 4.45 & 1.04 & Satisfied \\
\hline 5. & $\begin{array}{c}\text { I am satisfied with the } \\
\text { Privacy measures provided } \\
\text { by the health workers }\end{array}$ & 3.84 & 1.18 & Satisfied \\
\hline 6. & $\begin{array}{c}\text { I am satisfied with the Sex } \\
\text { of health worker(s) who } \\
\text { attended to me }\end{array}$ & 2.88 & 1.03 & Dissatisfied \\
\hline 7. & $\begin{array}{c}\text { I am satisfied with the Care } \\
\text { and support provided to my } \\
\text { baby by the health workers }\end{array}$ & 4.52 & 0.93 & Satisfied \\
\hline Aggregate mean & 3.98 & & \\
\hline
\end{tabular}

The table shows that the majority of the women were satisfied with the waiting time before been attended to $(X=3.49, S D=1.46)$, respect and courtesy by health workers ( $X=4.12, S D=1.47)$, amount of time spent on examination $(X=3, S D=1.3)$, competency and confident of the health worker $(X=4.45, S D=1.04)$, privacy measures provided by the health workers $(\mathrm{X}=3.84, \mathrm{SD}=1.18)$, as well as the care and support provided to their babies $(X=4.52, S D=0.93)$. 
However, most of them were dissatisfied with the sex of the health worker(s) who attended to them $(X=2.88, S D=1.03)$ (Table 4). The table shows that the majority of the women were satisfied with the status of their pregnancies whether wanted $(X=4.59, S D=0.94)$ or unwanted $(X=4.53, S D=1.03)$, spontaneous vaginal delivery as a mode of their delivery $(X=4.98, S D=1.41)$, a normal outcome of delivery $(X=4.50, S D=1.05)$, as well as a live fetal birth outcome $(X=4.19, \mathrm{SD}=1.31)$. However, most of them were dissatisfied with assisted delivery (vacuum, forceps and CS delivery) ( $\mathrm{X}=2.54$, $\mathrm{SD}=1.03)$, complicated outcome of delivery $(\mathrm{X}=2.76, \mathrm{SD}=1.26)$ and still birth \& neonatal death outcome of delivery $(X=2.98, S D=0.92)$.

Table 4: Maternal obstetrics history related maternal satisfaction with delivery services.

\begin{tabular}{|c|c|c|c|c|c|}
\hline $\mathbf{S} / \mathbf{N}$ & \multicolumn{2}{|l|}{ Items } & \multirow{2}{*}{$\begin{array}{l}\text { Mean } \\
4.59\end{array}$} & \multirow{2}{*}{$\begin{array}{c}\text { Standard Deviation } \\
0.94\end{array}$} & \multirow{2}{*}{$\begin{array}{l}\text { Remark } \\
\text { Satisfied }\end{array}$} \\
\hline & & Wanted & & & \\
\hline 1. & 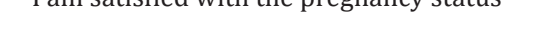 & Unwanted & 4.53 & 1.03 & Satisfied \\
\hline \multirow[b]{2}{*}{2.} & \multirow[b]{2}{*}{ I am satisfied with the mode of delivery } & SVD (Spontaneous Vaginal Delivery) & 4.98 & 1.41 & Satisfied \\
\hline & & $\begin{array}{c}\text { Assisted delivery (Vacuum, Forceps } \\
\text { or CS delivery) }\end{array}$ & 2.54 & 1.03 & Dissatisfied \\
\hline \multirow{2}{*}{3.} & \multirow{2}{*}{ I am satisfied with the outcome of the labor } & Normal & 4.50 & 1.05 & Satisfied \\
\hline & & Complicated & 2.76 & 1.26 & Dissatisfied \\
\hline \multirow{3}{*}{4.} & \multirow[b]{2}{*}{ I am satisfied with the fetal outcome } & Live birth & 4.19 & 1.31 & Satisfied \\
\hline & & $\begin{array}{c}\text { Others (Still birth and Neonatal } \\
\text { death) }\end{array}$ & 2.98 & 0.92 & Dissatisfied \\
\hline & & Aggregate mean & 3.89 & & \\
\hline
\end{tabular}

\section{Discussion}

A total of 158 post-natal women were approached. 144 completed the questionnaires out of which 102(70.8\%) are Muslims, and the other $42(29.2 \%)$ are Christians. Most of the respondents are within the age range of 30-39 years of age-71(49.3\%) and most of which were Hausas by tribe $57(39.6 \%)$. Most of the 144 respondents are married $122(84.7 \%)$ and are secondary education certificate (48-33.3) while few have Islamic education 21(14.6\%). The majority of the respondents were unemployed women-41 (28.5\%), students-36 (25\%) and government employees-35 (24.3\%). The respondents were satisfied with the number of health workers $(X=3.58, S D=1.4)$. This is in contrast to a study done in Malawi that showed a shortage of health care workers including health professionals and issues related to their retention were important barriers to their quality of care. Similarly, the majority of the women were satisfied with the waiting time before been attended to $(X=3.49, S D=1.46)$, this is in line with a study conducted in Assela Hospital. For the human dignity, majority of the women were satisfied with the respect and courtesy by health workers $(X=4.12, S D=1.47)$. This is in line with a study conducted in maternity referral hospital in Addis Ababa which found the attitude of the health workers to have a relative higher satisfaction score [10]. As found in this study $(X=3, S D=1.3)$, the above study also established women satisfaction with the amount of time spent on examination.

a. For the competency of the health workers, majority of the women demonstrated significant satisfaction $(X=4.45$, $\mathrm{SD}=1.04)$. This is in line with an Indian study that completeness of procedures, good medicine, and advice were perceived as 'good care' [11].

b. Majority of the women are satisfied with the privacy measures provided by the health workers $(X=3.84, S D=1.18)$. This is in line with a study from Debre Markos town indicated good level of maternal satisfaction with assurance of privacy (97.7\%) [12].

c. Majority of the women are satisfied with spontaneous vaginal delivery as a mode of their delivery $(X=4.98$, $\mathrm{SD}=1.41$ ). This is in conflict with a study in Debre Markos town demonstrated that spontaneous vaginal delivery was significantly associated with reduction of satisfaction on delivery care [13-16].

d. Majority of the women are satisfied with a normal outcome of delivery $(X=4.50, S D=1.05)$ and live fetal birth outcome $(X=4.19, S D=1.31)$. This is in line with a study from west-Arsi Oromiya, Assela showed that mothers with normal delivery and fetal outcome were two times more satisfied than those with complicated delivery and fetal outcome.

e. However, most of them were dissatisfied with assisted delivery (vacuum, forceps and CS delivery) ( $\mathrm{X}=2.54, \mathrm{SD}=1.03$ ). This is in contrast with a study from west-Arsi Oromiya, Assela which showed that mothers who had assisted vaginal delivery were less satisfied than mothers who had caesarian section (AOR=0.31, 95\% CI: 1.253, 4.5) [17-19].

\section{Implication of the Study}

The results of this study will provide scientific evidence regarding mothers' satisfaction with delivery care at UDUTH as performance measurement and also as consideration of satisfaction by health policy makers might be necessary for improving the quality of mother and newborn care, and reducing maternal mortality rate (MMR) and infant mortality rate (IMR) [19-22].

\section{Conclusion}

The above result concludes that there is a high level of maternal satisfaction with health workers and service delivery in UDUTH Sokoto. 


\section{Limitation}

a. The mothers were interviewed within the health centers, and they may give responses favoring the care providers resulting in social desirability bias.

b. The cross-sectional nature of the study does not allow the study to establish causal relationship between the different independent variables and the outcome variable.

c. Client satisfaction surveys are influenced by cultural response bias which is created by social and cultural factors that influence the way people perceive and respond to survey questions.

d. Absence of variables in the questionnaire to capture place of previous delivery that would have aided in cross-analysis of satisfaction.

\section{References}

1. Oyibocha E, Irinoye O, Sagua EO, Essien OT, Edeki JE, et al. (2014) Sustainable healthcare system in Nigeria: Vision, strategies and challenges. Journal of Economics and Finance 5(2): 28-39.

2. Say L, Chou D, Gemmill A, Tunçalp O, Moller B, et al. (2014) Global causes of maternal death: A WHO systematic analysis. The Lancet Global Health 2(6): e323-e333.

3. WHO (2016) The global strategy for women's, children's and adolescents' health, 2016-2030

4. Bertucci M, Boffo M, Mannarini S, Serena A, Saccardi C, et al. (2012) Assessing the perception of the childbirth experience in Italian women: a contribution to the adaptation of the childbirth perception questionnaire. Midwifery 28(2): 265-274.

5. Morris BJ, Jahangir AA, Sethi MK (2013) Patient satisfaction: An emerging health policy issue. AAOS Now 7(6): 29.

6. Srivastava A, Avan BI, Rajbangshi P, Bhattacharyya S (2015) Determinants of women's satisfaction with maternal health care: a review of literature from developing countries. BMC Pregnancy and Childbirth 15: 97.

7. National Institute for Health and Clinical Excellence (2017) Intrapartum care for healthy women and their babies during childbirth Clinical guideline.

8. Bitew K, Ayichiluhm M, Yimam K (2015) Maternal satisfaction on delivery service and its associated factors among mothers who gave birth in public health facilities of Debre Markos Town, Northwest Ethiopia. Biomed Res Int.
9. Buciuniene I, Blazeviciene A, Bliudziute E (2015) Health care reform and job satisfaction of primary health care physicians in Lithuania. BMC Fam Pract 6(1): 10.

10. Tadele M, Yirgu G, Daniel B, Dereje H (2014) Assessment of client satisfaction in labor and delivery services at a maternity referral hospital in Ethiopia. Pan Afr Med J 17: 76.

11. George A (2012) Quality of reproductive care in private hospitals in Andhra Pradesh: Women's perception. Economic Political Weekly 37: 1686-1692.

12. Ewunetu M, Mekonnen, Yalew WA, Anteneh ZA (2015) Women's satisfaction with childbirth care in Felege Hiwot referral hospital, Bahir Dar city, Northwest Ethiopia, 2014: Cross sectional study. BMC research notes 8: 528.

13. Azmeraw T, Zegeye DT, Yigzaw K (2011) Mothers' satisfaction with referral hospital delivery service in Amhara region, Ethiopia. BMC Pregnancy Childbirth 11: 78.

14. Yohannes B, Tarekegn M, Paulos W (2013) Mothers' utilization of antenatal care and their satisfaction with delivery services in selected public health facilities of Wolaita zone, Southern Ethiopia. International Journal of Scientific \& Technology Research 2(2).

15. Bruggemann OM, Parpinelli MA, Osis MUD, Cecatti JG, Netto ASC (2017) Support to woman by a companion of her choice during childbirth: A randomized controlled trial. Reprod Health 4: 5.

16. Chunuan SK, Kochapakdee WC (2013) Patient satisfaction with nursing care received during the intrapartum period. Thai J Nurs Res 7: 83-92.

17. Dzomeku MV (2011) Maternal satisfaction with care during labour: A case study of the Mampong-Ashanti district hospital maternity unit in Ghana. Int J Nurs Midwifery 3(3): 30-34.

18. Bhattacharyya S, Srivastava A, Avan BI (2013) Delivery should happen soon and my pain will be reduced: Understanding women's perception of good delivery care in India. Glob Health Action 6(1): 22635.

19. Samrawit S (2016) Perception of mothers and providers on the quality of care in maternal and newborn service in selected hospitals of Addis Ababa. AAU Institutional Repository.

20. Simin T, Morteza G, Saber A, Alikhah H, Bakhtiarzadeh K, et al. (2015) Assessment of mothers' satisfaction with the care of maternal care in specialized educational-medical centers in obstetrics and gynecological disease in Northwest Iran. J Anal Res Clin Med 3(2): 77-86.

21. Turan JM, Bulut A, Nalbant H, Ortayh N, Akalin AA (2016) The Quality of hospital-based antenatal care in Istanbul. Stud Fam Plann 37(1): 49-60.

22. WHO (2014) United nations children's fund, united nations population fund, The World Bank and the United Nations population division, trends in maternal mortality: 1990 to 2013 Estimates, WHO library cataloguing-in-publication data? 